\title{
Hip fracture care during Covid-19: a regional trauma centre's experience
}

\author{
Geoff Crozier-Shaw $^{1}$ (D) $\cdot$ Andrew J. Hughes ${ }^{1} \cdot$ Breda Conlon $^{1} \cdot$ Eoin Sheehan ${ }^{1} \cdot$ Khalid Merghani $^{1}$
}

Received: 8 September 2020 / Accepted: 14 December 2020 / Published online: 3 January 2021

(C) Royal Academy of Medicine in Ireland 2021

\begin{abstract}
Introduction The Covid-19 pandemic has caused worldwide upheaval from early 2020. Trauma and orthopaedic services are no different. A fundamentally important and significant portion of trauma services is the treatment of fragility fractures of the proximal femur, otherwise known as hip fractures. The hip fracture "Blue book Standards", the key performance indicators (KPIs) associated with appropriate hip fracture care are challenging during non-crisis times. We aim to review Blue Book compliance during the Covid-19 crisis and review outcomes of hip fractures, including Covid-19 infection rates.

Methods We retrospectively reviewed IHFD data to collection demographic data, IHFD standards of care, 30-day mortality rates and complications between 23rd March and 20th May 2020 and 2019. Covid-19 rates in 2020 were also recorded.

Results A total of 36 hip fractures were recorded in 2020, compared with 45 in 2019, resulting in a $20 \%$ reduction in presentations. Thirty-day mortality in hip fractures during the Covid-19 crisis was $8.3 \%$ compared with $2.2 \%$ in 2020. Covid-19 infection was statistically associated with 30 -day mortality in the 2020 cohort. Statistically significant improvements in timedependent KPIs (time to ward and time to surgery) were noted in the 2020 cohort.

Conclusions Despite improvements in hip fracture care KPIs, the Covid-19 crisis was associated with increased 30-day mortality in hip fracture patients. A positive Covid-19 swab was associated with higher mortality. These observations are of paramount importance to ensure adequate service planning and provision in the face of a potential "second wave" of Covid-19 infections leading into the winter months of 2020.
\end{abstract}

Keywords Age-related care $\cdot$ Covid-19 $\cdot$ Hip fractures $\cdot$ Orthopaedics $\cdot$ Osteoporosis trauma $\cdot$ Service improvement

\section{Introduction}

The year 2020 has been a year of unprecedented social, economic and healthcare upheaval. First identified in Wuhan province in China in December 2019, a novel coronavirus disease, named Covid-19 by the World Health Organisation, has wrought havoc on healthcare systems and impeded the delivery of trauma and orthopaedic care worldwide $[1,2]$.

Trauma and orthopaedic surgery services are no different and have been significantly impacted in terms of these services' response to the pandemic. Trauma management and survivability has a significant cause of morbidity, particularly in a population of advancing age. The median age of the

Geoff Crozier-Shaw

gcrozshaw@hotmail.com

1 Department of Trauma and Orthopaedics, Midland Regional Hospital, Tullamore, Co Offaly, Ireland trauma patient has significantly changed, with elderly trauma being a particular challenge [3, 4]. The fragility fracture of the proximal femur, otherwise called a "hip fracture", is of particular importance in the management of trauma in the elderly patient.

The British Orthopaedic Association and British Geriatric Society published their "Blue Book", a care pathway for patients with fragility fractures in 2007. This determined several key performance indicators (KPIs) for hip fracture care [5]. These have been adopted as the standards of care for hip fracture management within NHS and have also been adopted into KPIs for the Irish Hip Fracture Database [6]. Achieving these KPIs in hip fracture care minimises perioperative risk for these high-risk patients. These KPIs comprise six targets for hip fracture care, summarised in Table 1.

Since the introduction of the blue book standards in 2007, the 30-day mortality in hip fracture patients has reduced from 11.9 in 2003 to $7.8 \%$ in 2011 [7].

Covid-19 has presented significant challenges to hip fracture management and achieving the blue book standards. The 
typical hip fracture patient, typically elderly, often with significant comorbidities, is among the sector of society at greatest risk to Covid-19. Not only this, but elderly patients with hip fractures often are resident within or are discharged to nursing residential care units, which were particularly hard hit by Covid-19 in Ireland. Statistics show that almost one in five nursing home residents nationwide was infected with Covid$19[8,9]$.

With elderly people cocooning, going outside less and minimising a lot of their activities both inside and outside, one would expect there to be less hip fracture presentations during the "lockdown" isolation period for Covid-19 [10]. With ICU and capacity expanded nationwide, with use of operating theatres as potential intensive care overflow, access to theatre in a timely fashion has been a potential issue [11]. These factors, coupled with the general challenges of appropriate hip fracture care, place significant interest in the manner in which Covid-19 affected hip fracture rates and hip fracture care in Ireland during the periods March to May 2020, the most significant time period in which Covid-19 was being increasingly widespread and deadly.

We the authors aim to review and compare hip fracture rates, demographics in hip fracture patients and achievement of the Blue Book standards at a regional Irish trauma centre between the dates 16th March and 23rd May 2020 with a historical cohort of 16th March and 23rd May 2019.

\section{Methods}

Hip fracture care at a regional trauma centre over two was reviewed and compared for two periods of time, the 20th March to 20th May 2019 and 2020, respectively.

The 2020 cohort is the timeline for the worst of the Covid19 pandemic in Ireland. The 2019 cohort is a respective control.

The Irish Hip Fracture Database (IHFD) was consulted and reviewed for data on these time periods were studied and compared. The rates of Covid-19 infection, mortality and morbidities were also studied for the 2020 cohort.

Statistics analyses were carried out using IBM SPSS Statistics for Windows, version 24.0., Armonk, NY. Continuous data was assessed using Students' $T$ test and categorical data using two-tailed Chi-squared test with Yates correction.

\section{Results}

There were forty-five $(n=45)$ hip fractures that presented to this regional trauma centre for the period of time 23rd March to 20th May 2019. This same period in 2020, at the height of the Covid-19 pandemic, a total of thirty-six $(n=36)$ hip
Table 1 The "Blue Book" standards of care for hip fracture management

\begin{tabular}{ll}
\hline Standard 1 & Orthopaedic ward admission within $4 \mathrm{~h}$ \\
\hline Standard 2 & Definitive surgery within $48 \mathrm{~h}$ \\
Standard 3 & Pressure ulcer prevention \\
Standard 4 & Orthogeriatric care \\
Standard 5 & Bone health assessment \\
Standard 6 & Falls assessment \\
\hline
\end{tabular}

fractures presented to this regional trauma centre. This represents a 20\% reduction in hip fracture presentations to a regional trauma centre (Tables 2 ).

In 2019, the mean age of patients presenting with hip fractures was 79.5 years $( \pm 8.56$, range $61-98)$ with a median of 81 years.

Of the forty-five patients, twelve were male $(n=12)$ and thirty-three $(n=33)$ were female.

In 2020, the mean age of patients presenting with hip fractures was 79.34 years $( \pm 14.02$, range 33-97) with a median of 83.5 years.

Of the thirty-six patients, twelve $(n=12)$ and twenty-four $(n=24)$ were female.

For surgical versus conservative management, in 2019, $100 \%$ of patients were treated surgically $(n=45)$. In the same period in 2020, 97\% $(n=35)$ were treated surgically $(p=0.9$, chi-square with Yates).

In 2019, all hip fractures were managed locally, within the regional trauma centre. In 2020, three patients $(n=3)$ were transferred to a nearby private institution that had been taken over by HSE for the Covid-19 period. As such, 9\% of hip fractures were managed in a non-HSE hospital, and $91 \%$ were. The reason for this was for the purpose of timely surgical intervention and also to minimise potential Covid-19 exposure of these patients in the regional trauma centre.

Of all thirty-six patients who presented with hip fractures, $11 \%$ of patients $(n=4)$ tested positive for Covid-19. Of these four patients, one was managed conservatively due to significant perioperative risk. This patient had end-stage cardiac failure with severe aortic stenosis, coupled with the respiratory sequelae of Covid-19 (see Table 3).

Table 2 Demographics and 30-day mortality 2019 and 2020 cohorts

\begin{tabular}{llll}
\hline & 2019 & 2020 & $p$ value \\
\hline Mean age & $79.5 \pm 8.56$ & $79.36 \pm 11.02$ & $/$ \\
Female & 33 & 24 & $/$ \\
Male & 12 & 12 & $/$ \\
30-day mortality & $2.2 \%(n=1)$ & $8.3 \%(n=3)$ & 0.46 \\
\hline
\end{tabular}


Table 3 Covid-19-specific hip fractures statistics

\begin{tabular}{lll}
\hline & Rates & $p$ value \\
\hline Positive Covid-19 hip fractures & $11 \%(n=4)$ & $/$ \\
Covid-19 hip fracture mortality & $66 \%(n=2)$ & 0.02 \\
\hline
\end{tabular}

Italics represent statistically significant $p$ - values (less than 0.05 )

Of the thirty-six patients with hip fractures, three patients died $(8.3 \%)$ within 30 days of the hip fracture occurring. Of these three patients, two were swabbed positive for Covid-19. Covid-19 infectious status was statistically significant in terms of 30-day mortality ( $p=0.0064$, chi-squared with Yates). Of patients who died within 30 days of their injury, the mean age was $79.33( \pm 13.6)$, median 94 years. Two of these patients were female and one male. The one male patient was 64 years old and coupled with a positive Covid-19 swab, and had significant comorbidities including congestive cardiac failure, chronic renal insufficiency and cirrhosis (Table 2).

This compares with a single mortality within 30 days in the same time period in 2019 ( $p=0.46$, chi-squared with Yates). This represents a percentage of $2.2 \%$. This single patient was a 91-year-old nursing home resident who was classified as ASA-5 moribund by anaesthetics pre-operatively.

In 2020, of the thirty-six patients, four (11\%) had nonCovid-19-related respiratory post-operative complications. Of these, three responded to medical management and one required transfer to intensive care for non-invasive ventilation. One patient suffered post-operative atrial flutter requiring IV administration of anti-arrhythmic medication. One patient swabbed positive for Covid-19 did not die. He was a 49year old with an intertrochanteric femur fracture. He also required a post-operative transfusion.

For the time to ward admission KPI (less than $4 \mathrm{~h}$ ), in 2019, $20 \%$ of patients $(n=9)$ were admitted to the orthopaedic ward within $4 \mathrm{~h}$. This is compared with $47 \%(n=17)$ of patients during the Covid-19 period in 2020 ( $p=0.012$, chi-square with Yates).

For time to surgery within 48-h KPIs, in 2019, 57.8\% of patients fulfilled the KPIs $(n=26)$. In the same period in 2020 ,
$78 \%$ of the thirty-three patients $(n=28)$ treated at the regional trauma centre underwent fixation within the KPI time limit of $48 \mathrm{~h}(p=0.02$, chi-square with Yates).

For orthogeriatrician review KPIs, in 2019, 82.2\% $(n=37)$ of patients were reviewed by the regional hospital orthogeriatric service. In the same time period in $2020,86 \%$ of patients $(n=31)$ were reviewed by orthogeriatric services ( $p=0.86$, chi-square with Yates).

For pressure ulcer prevention KPIs, in 2019, 2.2\% $(n=1)$ of patients developed a pressure ulcer. This is compared with $0 \%(n=0)$ of patients in 2020 cohort $(p=0.36$, chi-square with Yates).

For falls assessment KPIs, in 2019, 80\% of patients ( $n=$ 36) had a falls assessment, compared with $86 \%(n=31)$ in 2020 ( $p=0.66$, chi-square with Yates).

For bone health assessment KPIs, in 2019, 82.2\% $(n=37)$ of patients had a falls assessment, compared with $86 \%(n=$ 31 ) in 2020 ( $p=0.86$, chi-square with Yates). All KPI data represented in Table 4.

\section{Discussion}

\section{Comparing our Covid-19 hip fracture cohort with international experience}

Through reviewing hip fracture presentations during the height of the Covid-19 pandemic, it is clear that the hip fracture burden from shear numbers' perspective was significantly reduced. Comparing numbers with a similar time period in 2019 , there was a $20 \%$ reduction in hip fracture presentations. This does appear to be consistent with other jurisdictions, which have noted a $32 \%$ reduction in trauma presentations during the Covid-19 pandemic [12].

Eleven percent $(n=4)$ of our reviewed hip fractures were diagnosed Covid-19 positive, of which $50 \%(n=2)$ died. Comparing with data from a northern Italian trauma centre, sixteen patients with hip fractures presented acutely with respiratory failure that was determined to be due to Covid-19. Three patients passed away prior to surgical fixation. Four patients passed away after fixation [13]. In Spain, another
Table 4 Blue Book standards 2019 and 2020 cohorts

\begin{tabular}{llll}
\hline & 2019 & 2020 & $p$ value \\
\hline Standard 1-ward admission & $20 \%(n=9)$ & $47 \%(n=17)$ & 0.012 \\
Standard 2-time to surgery & $57.8 \%(n=26)$ & $78 \%(n=28)$ & 0.02 \\
Standard 3-ulcer prevention & $2.2 \%(n=1)$ & $0 \%(n=0)$ & 0.36 \\
Standard 4-orthogeriatric review & $82.2 \%(n=37)$ & $86 \%(n=31)$ & 0.86 \\
Standard 5-bone health Assessment & $82.2 \%(n=37)$ & $86 \%(n=31)$ & 0.86 \\
Standard 6-falls assessment & $80 \%(n=36)$ & $86 \%(n=31)$ & 0.66 \\
\hline
\end{tabular}

Italics represent statistically significant $p$ - values (less than 0.05 ) 
nation hard-hit by Covid-19, a study of recent hip fracture data from 13 major trauma hospitals demonstrated their experience in managing hip fractures during the Covid-19 pandemic. Of 136 patients with hip fractures during March and April 2020, 124 patients were managed surgically and 12 were managed non-operatively. Mortality rates were $9.6 \%$ and 23 of 136 were Covid-19 positive [14].

The Chinese experience, particularly that in Wuhan, the epicentre of the pandemic, is interesting. An early study of 10 hip fractures with Covid-19 showed mortality of $40 \%$ [15]. A British study showed hip rates of mortality in hip fractures during Covid-19 pandemic compared with a historical-matched cohort (13.3 versus 6.6\%). None of these patients was diagnosed to be Covid-19 positive [16].

\section{Changing paradigms of hip fracture management in Covid-19}

The approach to managing severely co-morbid hip fracture patients with Covid-19 does call into question previous paradigms of care in hip fracture management. A Cochrane review in 2008 does mention that there is no high-level evidence comparing conservative versus surgical management due to high levels of surgical management but does mention that rehabilitation and length of stays for surgically managed patients are likely to be significantly improved and shorter, respectively [17]. A consensus statement from the anaesthetic and intensive care societies in the UK does mention that in very unwell Covid-19 patients, non-surgical management can be considered [18]. The Chinese experience does mention that non-surgical management can be considered in very unwell Covid-19 patients [19]. Our experience of Covid-19 patients with hip fractures demonstrates the whole spectrum of the Covid-19 illness. A patient with severe $\mathrm{CCF}$ and respiratory compromise was deemed by consensus opinion between surgeons and anaesthetics to be too high risk for surgical management and was managed conservatively. In our studied cohort, Covid-19 infection was significantly associated with a 30-day post-operative mortality risk with $11 \%$ of hip fractures being swabbed positive for Covid-19 and 66\% of these patients dying within 30 days of admission. This was a total of 8.3\% 30-day mortality. Comparing this with the 30-day mortality rates for hip fractures in the same time period in 2019 showed mortality of $2.2 \%$. This was however not statistically significant ( $p=0.5$, chi-squared with Yates). These new data are worthwhile considering and allow for pre-operative counselling of patients and families of Covid-positive hip fractures.

\section{The blue book standards in context of Covid-19}

Timely hip fracture care is fundamental to minimising morbidity and mortality associated with hip fractures. Previous studies have shown the 30-day mortality rate for these injuries can be as high as $10 \%$, with reported 1-year mortality of $30 \%$ [20]. More recent data since the introduction of blue book standards have improved these statistics with hip fractures that undergo fixation after $48 \mathrm{~h}$ having significantly higher levels of mortality and morbidities. A cohort of 6036 hip fractures, surgical intervention before $48 \mathrm{~h}$ exhibited a lower overall complication rate $(p=0.034)$. Mortality rates increased with delay to surgery $(p=$ 0.039 ). Another meta-analysis of 13,478 patients showed significant reduction in mortality rates for earlier surgical intervention [21, 22]. Covid-19 presented significant challenges for mortality in our 2020 cohort, with the 30-day mortality for hip fracture patients increasing almost fourfold (2.2 to $8.3 \%$ ) comparing 2019 and 2020. Sixty-six percent ( $n$ = 2) of hip fracture mortality were associated with Covid-19 diagnosis. Of these, one underwent fixation within the 48-h window, and one did not.

Despite statistically significant rates of improvement in 2020 compared with 2019 for time to ward, time to surgery and orthogeriatrician review, the Covid-19 pandemic has increased the mortality associated with hip fractures (albeit not statistically significantly).

\section{Conclusions}

The period March to May 2020 during the height of Covid-19 pandemic has significantly reduced the hip fracture burden compared with a matched historical cohort in 2019. Similar observations have been made internationally. While hip fracture KPIs were achieved at higher rates compared with 2019, 30-day mortality was higher, although this increase was not statistically significant. Within the 2020 cohort, a positive Covid-19 test was associated with significantly increased risk of 30-day mortality. One hip fracture with a positive Covid-19 swab was managed conservatively. International experience has shown a similar approach and consideration of nonsurgical management of compromised and co-morbid hip fractures with Covid-19 diagnosis.

The data from this study show the challenges Covid-19 has posed for orthopaedic surgeons, intensivists, anaesthetists and orthogeriatricians. Despite improving standards in hip fracture KPIs, mortality has increased during the Covid-19 pandemic for these challenging patients. This is of great importance, particularly in the context of a Covid-19 "second wave" which could occur leading into the winter months of 2020, a time of year long associated with increases in fragility fracture presentations.

\section{Limitations}

Service adaptations in the face of Covid-19 crisis do lead to some discrepancies with data. The transfer of three hip fractures to another hospital under the temporary control of the 
HSE is both to facilitate their surgical fixation and minimise their risk of contracting Covid-19 while an inpatient in the regional trauma hospital does lead to a discrepancy both in terms of time to admission to orthopaedic ward, orthogeriatric review, falls and bone health assessment. Data issues with errors in documenting the time of presentation to the emergency department, as opposed to the time of admission, through audit of the Irish Hip Fracture Database (IHFD), have been proven in the Irish setting. Strict documentation hygiene by the admitting team is paramount so as to allow accurate audit, given that national policies are based on the data produced by the IHFD [23].

Authors' contributions All authors complied with standards and guidelines of ICMJE in relation to their contributions to the planning, data gathering, writing and review of this paper.

\section{Compliance with ethical standards}

Conflict of interest The authors declare that they have no conflict of interest.

\section{Code availability N/A}

Ethics approval Audit-type activity and thus ethical approval are neither needed nor sought as per the Health Service Executive Guidelines on clinical audit.

\section{References}

1. World Health Organisation (WHO) (2020) Novel coronavirus China. https://www.who.int/emergencies/diseases/novelcoronavirus-2019. Accessed 21st Sept 2020

2. Huang C, Wang Y, Li X et al (2020) Clinical features of patients infected with 2019 novel coronavirus in Wuhan, China. Lancet 395(10223):497-506. https://doi.org/10.1016/S0140-6736(20) 30183-5

3. Gioffrè-Florio M, Murabito LM, Visalli C et al (2018) Trauma in elderly patients: a study of prevalence, comorbidities and gender differences. G Chir 39(1):35-40. https://doi.org/10.11138/gchir/ 2018.39.1.035

4. Llompart-Pou JA, Pérez-Bárcena J, Chico-Fernández M, SánchezCasado M, Raurich JM (2017) Severe trauma in the geriatric population. World J Crit Care Med 6(2):99-106. https://doi.org/10. 5492/wjccm.v6.i2.99

5. Care of Patients with Fragility Fracture (2007) British Orthopaedic Association and British Geriatric Society. https://www.bgs.org.uk/ sites/default/files/content/attachment/2018-05-02/Blue\%20Book\% 20 on $\% 20$ fragility $\% 20$ fracture $\% 20$ care.pdf. Accessed $21^{\text {st }}$ Sept 2020

6. Irish Hip Fracture Database National Report 2017 (2017) National Office of Clinical Audit (NOCA). https://www.noca.ie/documents/ ihfd-national-report-2017. Accessed on 21st Sept 2020

7. Wilson H (2017) Orthogeriatrics in hip fracture. Open Orthop J 11: 1181-1189. https://doi.org/10.2174/1874325001711011181

8. Horgan-Jones J (2020) The human cost of Covid-19: Ireland's care homes with the most deaths revealed. The Irish Times. https:// www.irishtimes.com/news/ireland/irish-news/the-human-cost-of- covid-19-ireland-s-care-homes-with-the-most-deaths-revealed-1 . 4264170. Accessed 21st Sept 2020

9. Mills G, Moore-Cherry N, Foley R (2020) Making sense of publicly available data on COVID-19 in Ireland. MedRxIV. https:// www.medrxiv.org/content/10.1101/2020.05.13.20101089v1. Accessed 21st Sept 2020

10. Cocooning during Covid-19 (2020) Government of Ireland. https:// www.citizensinformation.ie/en/health/covid19/cocooning during covid19.html\#: :text=Cocooning $\% 20$ involves $\% 20$ staying\% $\%$ at $\%$ 20home, COVID \%2D19\%2C\%20you $\% 20$ should $\% 3$ A\&text $=$ Keep $\% 20$ your $\% 20$ physical $\% 20$ distance $\% 20$ and $\% 20$ use $\%$ 20 face $\% 20$ coverings $\% 20$ when $\% 20$ you $\% 20$ have $\% 20$ visitors. Accessed $21^{\text {st }}$ Sept 2020

11. Ireland's action plan in response to Covid-19 (2020) Government of Ireland. https://www.gov.ie/en/publication/47b727-governmentpublishes-national-action-plan-on-covid-19/. Accesssed $21^{\text {st }}$ Sept 2020

12. Hernigou J, Morel X, Callewier A, Bath O, Hernigou P (2020) Staying home during "COVID-19" decreased fractures, but trauma did not quarantine in one hundred and twelve adults and twenty eight children and the "tsunami of recommendations" could not lockdown twelve elective operations. Int Orthop 44(8):14731480. https://doi.org/10.1007/s00264-020-04619-5

13. Catellani F, Coscione A, D'Ambrosi R et al (2020) Treatment of proximal femoral fragility fractures in patients with COVID-19 during the SARS-CoV-2 outbreak in Northern Italy. J Bone Joint Surg Am 102(12):e58. https://doi.org/10.2106/JBJS.20.00617

14. Munoz Vives JM, Jornet-Gibert M, Camara-Cabrera J et al (2020) Mortality rates of patients with proximal femoral fracture in a worldwide pandemic: preliminary results of the Spanish HIPCOVID observational study

15. Liu J, Mi B, Hu L et al (2020) Preventive strategy for the clinical treatment of hip fractures in the elderly during the COVID-19 outbreak: Wuhan's experience. Aging (Albany NY) 12(9):7619-7625. https://doi.org/10.18632/aging.103201

16. Williams JT, Kumar A (2020) The effect of the COVID-19 pandemic on hip fracture care. Transient Journal of Orthopaedics in Time of Coronavirus. British Orthopaedic Association. April

17. Handoll HH, Parker MJ (2008) Conservative versus operative treatment for hip fractures in adults. Cochrane Database Syst Rev 3: CD000337. https://doi.org/10.1002/14651858.CD000337.pub2

18. Checketts M, Freeman N, Harrop-Griffiths W et al (2020) Perioperative care of patients with hip and major fragility fractures during the COVID-19 pandemic. A consensus statement from the Faculty of Intensive Care Medicine, Intensive Care Society, Association of Anaesthetists and Royal College of Anaesthetists. Faculty of Intensive Care Medicine, Intensive Care Society, Association of Anaesthetists and Royal College of Anaesthetists. https://icmanaesthesiacovid-19.org/consensus-statement-onperioperative-care-of-patients-with-hip-and-major-fragilityfractures. Accessed 21st Sept 2020

19. Mi B, Chen L, Xiong Y, Xue H, Zhou W, Liu G (2020) Characteristics and early prognosis of COVID-19 infection in fracture patients. J Bone Joint Surg Am 102(9):750-758. https://doi. org/10.2106/JBJS.20.00390

20. Parker MJ, Anand JK (1991) What is the true mortality of hip fractures? Public Health 105(6):443-446. https://doi.org/10.1016/ s0033-3506(05)80614-6

21. Alvi HM, Thompson RM, Krishnan V et al (2018) Time-to-surgery for definitive fixation of hip fractures: a look at outcomes based upon delay. Am J Orthop (Belle Mead NJ) 47(9). https://doi.org/ 10.12788/ajo.2018.0071

22. Simunovic N, Devereaux PJ, Sprague S et al (2010) Effect of early surgery after hip fracture on mortality and complications: systematic review and meta-analysis. CMAJ 182(15):1609-1616. https:// doi.org/10.1503/cmaj.092220 
23. Hughes AJ, Hennessy O, Brennan L, Rana A, Murphy CG (2019) How accurate is the data provided to the Irish hip fracture database? Ir J Med Sci 188(1):13-18. https://doi.org/10.1007/s11845-018$1810-5$
Publisher's note Springer Nature remains neutral with regard to jurisdictional claims in published maps and institutional affiliations. 